\title{
Common Carotid Artery Stiffness Is Associated with Left Ventricular Structure and Function and Predicts First Hospitalization for Acute Heart Failure
}

\author{
Shih-Hsien Sung ${ }^{a, c}$, do-Nan Liao ${ }^{a, c}$ Wen-Chung Yu ${ }^{a, c}$ \\ Hao-Min Cheng ${ }^{b, c}$ Chen-Huan Chen ${ }^{b, d}$ \\ a Division of Cardiology, Department of Medicine, and ${ }^{b}$ Department of Medical Research \\ and Education, Taipei Veterans General Hospital, ' Cardiovascular Research Center, and \\ ${ }^{d}$ Institute of Public Health and Community Medicine Research Center, National Yang-Ming \\ University, Taipei, Taiwan, ROC
}

\section{Key Words}

Common carotid artery · Speckle tracking · Arterial stiffness · Left ventricular function ·

Acute heart failure

\begin{abstract}
Aims: Proximal aortic stiffness may be more important than carotid-femoral pulse wave velocity (cf-PWV) in the pathogenesis of heart failure. The present study investigated the associations of common carotid artery (CCA) stiffness, which might be a surrogate for proximal aortic stiffness, with left ventricular (LV) structure and function, and the development of acute heart failure (AHF). Methods and Results: Outpatients without a history of heart failure (114 subjects aged $63.5 \pm 17.5$ years) were enrolled for comprehensive noninvasive cardiovascular examinations. The LV mass index, the LV ejection fraction (EF), and the ratio of the early diastolic transmitral flow velocity to the early septal mitral annular diastolic velocity $\left(E / E^{\prime}\right)$ were measured by echocardiography. CCA mechanical properties, including the incremental elastic modulus (Einc), $\beta$ stiffness index, CCA distensibility (CD) and circumferential strain (CS), were assessed by carotid artery ultrasonography. Cf-PWV was measured by arterial tonometry. CD was significantly associated with the LV mass index, and all CCA stiffness indices were significantly associated with $\mathrm{EF}$ and $\mathrm{E} / \mathrm{E}^{\prime}$ independently of age, mean blood pressure, and cf-PWV. During a mean follow-up of $265 \pm 106$ days, 9 patients presented with AHF. Einc (hazard ratio $6.56,95 \%$ confidence interval $1.64-26.26$, by quartile analysis), CS $(6.82,1.70-27.35)$, and $\beta$
\end{abstract}


Sung et al.: Common Carotid Artery Stiffness Is Associated with Left Ventricular

stiffness index $(3.91,1.05-14.57)$ but not cf-PWV $(1.62,0.41-6.51)$ significantly predicted the events. Conclusions: In patients at risk for heart failure, CCA stiffness was significantly associated with LV structure and function independently of cf-PWV. In addition, CCA stiffness but not cf-PWV predicted first AHF.

(C) 2014 S. Karger AG, Basel

\section{Introduction}

The left ventricle pumps pulsatile flow into the arterial system, which functions as both a conduit and a reservoir so that the peripheral tissue and end organs receive blood supply with minimal pulsatility. The arterial function declines with stiffening of large arteries, the aorta in particular, mainly due to the aging process. Increased central aortic stiffness has been identified as an independent risk factor for heart failure [1-3] and end-organ damage [4], likely due to the increased afterload on the heart, and the harmful effect of excessive pressure and flow pulsatility in the peripheral microcirculation.

Carotid-femoral pulse wave velocity (cf-PWV) measures the stiffness over a large part of the aorta but spares the ascending aorta, which may play a pivotal role in the pathogenesis of heart failure $[3,5,6]$. Although cf-PWV is associated with various indices of left ventricular (LV) structure and function [7] and is increased in patients with heart failure and preserved ejection fraction (EF) $[8,9]$, few epidemiological studies directly support that high baseline cf-PWV predicts future development of heart failure [10,11].

Common carotid arteries (CCA) are usually considered as part of the central conductance vessels rather than the peripheral muscular arteries, due to their high content of elastin and close proximity to the ascending aorta $[12,13]$. However, there is an impedance mismatch between the more compliant ascending aorta and the stiffer CCA in young, healthy adults, which may serve to reduce the harmful effect of pressure and flow pulsatility on the cerebral microcirculation [14]. Measures of the CCA stiffness have been associated with risk of ischemic stroke and dementia but not of coronary artery disease [14-18]. However, with advancing age, disproportionately increased proximal aortic stiffness may match the stiffness of CCA [14], reduce the impedance mismatch, and tighten the link between CCA stiffness and LV structure and function $[9,19]$. In this context, measures of the CCA stiffness may become a surrogate for ascending aortic stiffness and provide additional information on the pathogenesis of heart failure beyond cf-PWV, an index of arterial aging $[9,20]$. Therefore, in the present study, we investigated the associations of mechanical properties of the CCA with indices of LV structure and function, and development of acute heart failure (AHF) in subjects without a history of heart failure.

\section{Methods}

\section{Study Population}

Patients without typical signs (e.g. elevated jugular venous pressure, pulmonary crackles, and displaced apex beat) [21] or history of heart failure were eligible to be included in the present study. The study population consisted of 114 patients that were consecutively enrolled due to showing possible structural or functional reasons for the development of heart failure [22], among 259 subjects who were primarily invited to participate in a prospective study investigating the associations between vascular aging and renal functions. Patients with uncontrolled hypertension, uncontrolled diabetes mellitus, and documented history of myocardial infarction within 1 month were excluded. To be eligible for the present study, patients with atrial fibrillation, valvular heart disease, recent stroke (within 3 months) or established peripheral artery disease were also excluded. The investigation conformed to the principles outlined in the Declaration of Helsinki. A written informed consent approved by our institutional review board was obtained from each patient before enrollment. 
Sung et al:: Common Carotid Artery Stiffness Is Associated with Left Ventricular

\section{Study Protocol}

All participants underwent a comprehensive echocardiographic study including carotid artery sonography, and assessments of arterial stiffness and wave reflections. Data of the patients' medical history, including hypertension, diabetes and coronary artery disease, and demographics were recorded. Coronary artery disease was diagnosed by history of cardiac catheterization. The estimated glomerular filtration rate was calculated by using a modified Modification of Diet in Renal Disease equation based on the Chinese population [23].

\section{Measurements of LV Structure and Function}

LV mass (LVM) and LV end-diastolic volume (LVEDV) indexed to the body surface area, and LV EF were calculated from the M-mode measurements and biplane Simpson's method using a multifrequency transducer incorporated in an Artida Echocardiograph (Toshiba Medical Systems Corporation, Tokyo, Japan). The $\mathrm{LV}$ relative wall thickness was calculated as the ratio of $2 \times$ posterior wall thickness to LV end-diastolic internal dimension. The ratio of early to late diastolic transmitral inflow velocity (E/A) was measured by Doppler sampling between the tips of the anterior and posterior mitral leaflets. Deceleration time of the early diastolic flow velocity was also measured. Early diastolic velocity of the septal mitral annulus (E') was recorded in the apical four-chamber view using the tissue Doppler technique. E/E' was the ratio of the early diastolic transmitral flow velocity to the early septal mitral annular diastolic velocity. All measures were the average of 4 consecutive beats.

Patients with an $\mathrm{LV} \mathrm{EF}<45 \%$ were considered to have systolic dysfunction [24]. Patients with a diastolic dysfunction had an LV EF $\geq 45 \%$ and met the following criteria: (1) LVEDV index $<97 \mathrm{ml} / \mathrm{m}^{2}$ and E/E' $>15$, or (2) LVEDV index $<97 \mathrm{ml} / \mathrm{m}^{2}, 8<\mathrm{E} / \mathrm{E}^{\prime}<15$, and abnormal $\mathrm{LV}$ filling $\left(\mathrm{E} / \mathrm{A}_{>50 \text { years }}<0.5\right.$, deceleration time $_{>5 \text { yyears }}>280 \mathrm{~ms}$ ), or (3) LVEDV index $<97 \mathrm{ml} / \mathrm{m}^{2}, 8<\mathrm{E} / \mathrm{E}^{\prime}<15$, and LVM index $>122 \mathrm{~g} / \mathrm{m}^{2}$ in women or $>149 \mathrm{~g} / \mathrm{m}^{2}$ in men $[21,24]$. The remaining subjects were categorized as having normal LV function.

\section{Measurements of Arterial Stiffness and Wave Reflections}

Supine brachial systolic (SBP) and diastolic (DBP) blood pressures, and simultaneous right CCA and right femoral arterial pressure waveforms were obtained with a commercially available device using the oscillometric and arterial tonometric techniques (VP-2000, Colin Corporation, Komaki, Japan) [25]. The difference between SBP and DBP was pulse pressure (PP). Brachial mean blood pressure (MBP) was calculated as DBP plus 1/3 PP. cf-PWV was calculated as the travelling distance between the right CCA and right femoral artery divided by the foot-to-foot pulse transit time [25]. Carotid SBP was the peak value of an ensemble-averaged carotid artery pressure waveform calibrated to brachial DBP and MBP [25]. Carotid augmentation index ( $\mathrm{CAI}$ ) was calculated by identification of the inflection point on the pressure waveform [25]. Intra- and interobserver reproducibility was evaluated in 20 randomly selected patients by calculating the intraclass correlation coefficient (ICC). The intra- and interobserver ICCs were 0.989 and 0.988 for cf-PWV, and 0.999 and 0.984 for cAI, respectively.

Two-dimensional grayscale images of the right CCA were swept from the proximal CCA to the carotid bifurcation to survey the CCA anatomy using a 7.5-Hz linear transducer incorporated in the Artida Echocardiograph. Cine loops of transverse CCA at the level of approximately $1 \mathrm{~cm}$ proximal to the carotid bulb were acquired for the online analyses using the premounted software in the Artida Echocardiograph (Toshiba Medical Systems Corporation).

On images of the cross-sectional CCA, the image frame at the end of the electrical diastole (start of QRS wave) was identified, and the vessel on this frame was manually marked with a contour at the lumen-intima boundary (fig. 1). The circumferential strain (CS) was then obtained to represent the prolongation along the circular perimeter of the carotid artery in the systole. The intra- and interobserver ICCs for CS were 0.998 and 0991, respectively.

Two-dimensional long-axis grayscale cine loops of the right CCA were also obtained, and the CCA systolic and diastolic diameters as well as the intima-media thickness of the posterior wall at the same level were measured. CCA incremental elastic modulus (Einc) [7] was calculated according to the equation: Einc = $\left(4 a^{2} b \Delta P\right) /\left[\left(b^{2}-a^{2}\right) \Delta D\right]$, where ' $a$ ' is the internal radius, 'b' the external radius of the wall obtained from the sonogram, and ' $\Delta \mathrm{P}$ ' and ' $\Delta \mathrm{D}$ ' are the CCA pressure and diameter changes over the cardiac cycle [7]. CCA distensibility (CD) was obtained according to the formula: $C D=2[(\mathrm{Ds}-\mathrm{Dd}) / \mathrm{Dd}] / \Delta \mathrm{P}[26]$, where 'Ds' and 'Dd' are CCA systolic and diastolic diameters. $\beta$ stiffness index was calculated using the equation: $\ln (\mathrm{SBP} / \mathrm{DBP}) /$ [(Ds - Dd)/Dd], where SBP and DBP are brachial blood pressures [27]. The intra- and interobserver ICCs were 0.994 and 0.978 for Einc, 0.986 and 0.943 for CD, and 0.995 and 0.959 for $\beta$ stiffness index, respectively. 


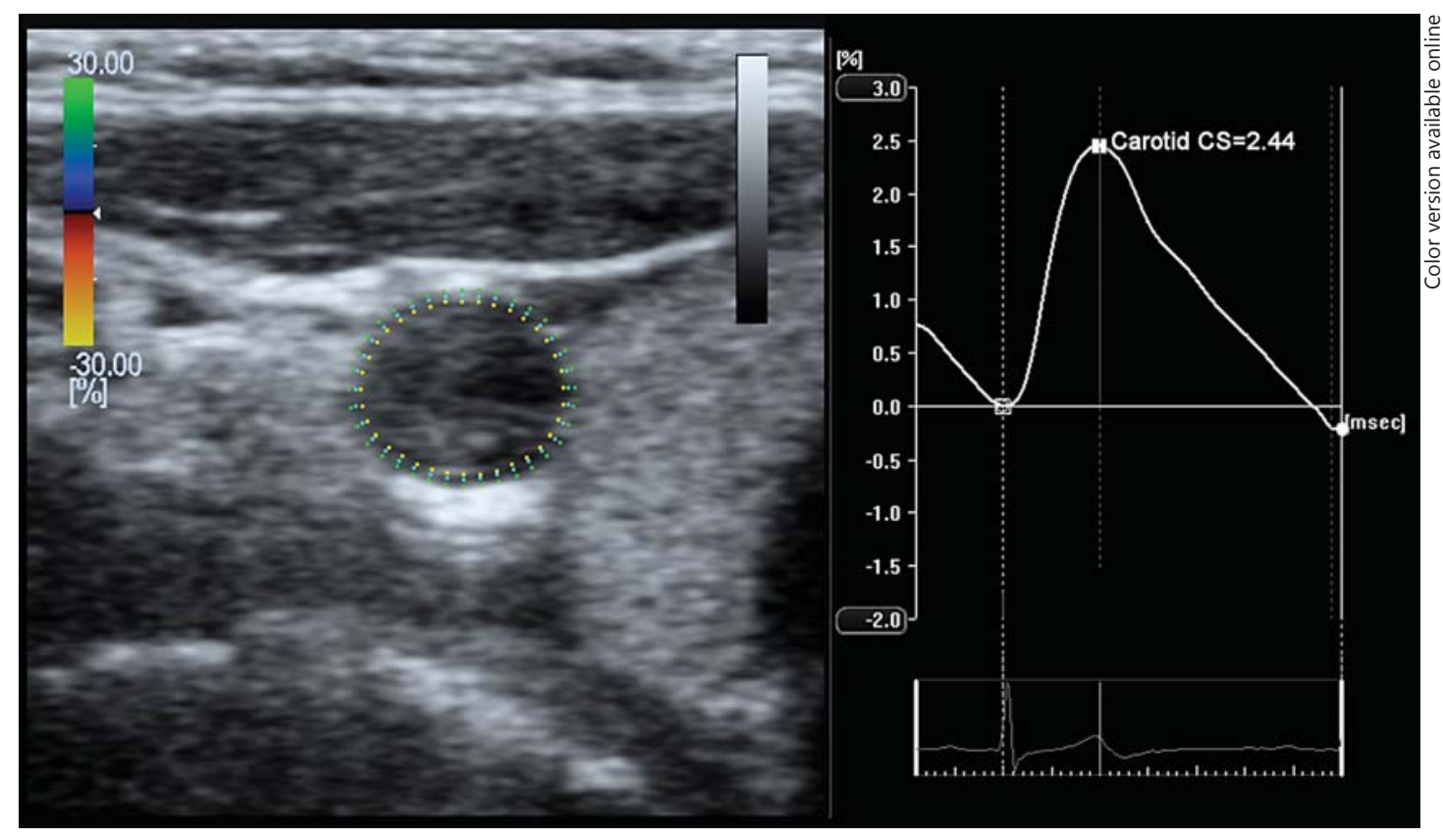

Fig. 1. An example showing the measurement of CS of the CCA.

\section{Follow-Up}

Patients were followed up at outpatient clinics or by regular telephone consultations for up to 1 year to check if there were any adverse cardiovascular events including hospitalization due to AHF and death. These adverse cardiovascular events were confirmed by review of medical records by an independent investigator (J.N.L.) who was blinded to the measurements of cardiovascular function. AHF was verified based on the simultaneous presence of at least 2 major Framingham criteria for congestive heart failure [28] or an elevated $\mathrm{N}$-terminal pro-brain natriuretic peptide level if available. The period of event-free survival was defined as the interval between the cardiovascular evaluation and the date of the first adverse event or the end of follow-up.

\section{Statistical Analysis}

Between-group comparisons were performed using one-way ANOVA with Bonferroni post hoc analysis or $\chi^{2}$ test, where appropriate. Multiple linear regression analysis was used to describe the associations between various indices of global and regional arterial stiffness, and LV structure and function, after accounting for age and brachial MBP, and even cf-PWV. Collinearity in the multiple linear regression models was examined by calculating the variance inflation factor. No significant collinearity was found in any of the multiple linear regression models. Significant indicators of impaired cardiac function, defined as systolic or diastolic dysfunction, identified from the univariate binary logistic regression analysis, were further examined in the multiple regression models. The quartile values of each variable were tested to evaluate the best cutoff value for the prediction of AHF. The Kaplan-Meier survival analysis with a log rank test was used to characterize the clinical impact of the CCA stiffness indices. Statistical significance was set at $\mathrm{p}<0.05$ and all statistical analyses were carried out using SPSS 15.0 (SPSS Inc., Chicago, Ill., USA).

\section{Results}

Among the 114 eligible patients (mean age $63.5 \pm 17.5$ years, 30 females), 25 patients had LV systolic dysfunction, 29 had LV diastolic dysfunction, and 60 had normal LV function. Their baseline characteristics are shown in table 1. More patients with LV systolic dysfunction appeared to have prevalent diabetes and coronary artery disease, and more patients with 
Sung et al.: Common Carotid Artery Stiffness Is Associated with Left Ventricular Structure and Function and Predicts First Hospitalization for Acute Heart Failure

Table 1. Clinical characteristics, cardiovascular measurements, and mechanical properties of CCA in the study population with and without LV systolic and diastolic dysfunction

\begin{tabular}{|c|c|c|c|c|}
\hline Variable & $\begin{array}{l}\text { Systolic dysfunction } \\
(\mathrm{n}=25)\end{array}$ & $\begin{array}{l}\text { Diastolic dysfunction } \\
(\mathrm{n}=29)\end{array}$ & $\begin{array}{l}\text { Normal LV function } \\
(n=60)\end{array}$ & $\mathrm{p}$ value \\
\hline Age, years & $62.9 \pm 16.6$ & $69.7 \pm 12.2$ & $60.8 \pm 19.5$ & 0.081 \\
\hline Male gender, \% (n) & $84(21)$ & $69(20)$ & $72(43)$ & 0.400 \\
\hline \multicolumn{5}{|l|}{ Past medical history, \% (n) } \\
\hline Hypertension & $64(16)$ & $66(19)$ & $50(30)$ & 0.278 \\
\hline Diabetes & $48(12)$ & $28(8)$ & $12(7)$ & 0.001 \\
\hline CAD & $88(22)$ & $45(13)$ & $12(7)$ & $<0.001$ \\
\hline Smoking & $68(17)$ & 45 (13) & $38(23)$ & 0.043 \\
\hline eGFR, $\mathrm{ml} / \mathrm{min} / 1.73 \mathrm{~m}^{2}$ & $76.4 \pm 28.1$ & $73.0 \pm 28.0$ & $85.2 \pm 33.6$ & 0.183 \\
\hline \multicolumn{5}{|l|}{ Medications } \\
\hline ACEI/ARB, \% (n) & $84(21)$ & $48.3(14)$ & $35(21)$ & $<0.001$ \\
\hline$\beta$-Blockers, \% (n) & $84(21)$ & $58.6(17)$ & $25(15)$ & $<0.001$ \\
\hline $\mathrm{CCB}, \%(\mathrm{n})$ & $20(5)$ & $27.6(8)$ & 31.7 (19) & 0.550 \\
\hline Diuretics, \% (n) & $68(17)$ & $37.9(11)$ & $16.7(10)$ & $<0.001$ \\
\hline$\alpha$-Blockers, \% (n) & $8(2)$ & $31(9)$ & $15(9)$ & 0.064 \\
\hline \multicolumn{5}{|c|}{ Brachial and central blood pressures } \\
\hline Brachial SBP, mm Hg & $117 \pm 19^{b}$ & $133 \pm 20$ & $126 \pm 18$ & 0.013 \\
\hline Brachial DBP, mm Hg & $70 \pm 9^{b}$ & $78 \pm 13$ & $74 \pm 11$ & 0.025 \\
\hline Brachial PP, mm Hg & $48 \pm 13$ & $55 \pm 13$ & $52 \pm 13$ & 0.149 \\
\hline Brachial MBP, mm Hg & $86 \pm 12^{\mathrm{b}}$ & $96 \pm 14$ & $91 \pm 12$ & 0.010 \\
\hline Heart rate, beats/min & $76 \pm 16^{\mathrm{a}, \mathrm{b}}$ & $64 \pm 13$ & $65 \pm 9$ & $<0.001$ \\
\hline Carotid SBP, mm Hg & $110 \pm 16^{\mathrm{b}}$ & $122 \pm 18$ & $114 \pm 17$ & 0.039 \\
\hline Carotid PP, mm Hg & $38 \pm 12$ & $44 \pm 12$ & $39 \pm 11$ & 0.128 \\
\hline \multicolumn{5}{|c|}{ Cardiac structure and function } \\
\hline LVM index, $\mathrm{g} / \mathrm{m}^{2}$ & $159 \pm 56^{\mathrm{a}}$ & $147 \pm 70^{\mathrm{a}}$ & $94 \pm 25$ & $<0.001$ \\
\hline LV RWT & $0.33 \pm 0.09^{a, b}$ & $0.50 \pm 0.26$ & $0.46 \pm 0.17$ & 0.002 \\
\hline LVEDV index, $\mathrm{ml} / \mathrm{m}^{2}$ & $95 \pm 35^{\mathrm{a}, \mathrm{b}}$ & $55 \pm 17^{\mathrm{a}}$ & $43 \pm 12$ & $<0.001$ \\
\hline $\mathrm{LV}$ EF, $\%$ & $31 \pm 78^{\mathrm{a}, \mathrm{b}}$ & $60 \pm 10^{\mathrm{a}}$ & $65 \pm 8$ & $<0.001$ \\
\hline $\mathrm{E} / \mathrm{A}$ & $1.5 \pm 0.6^{\mathrm{a}, \mathrm{b}}$ & $0.9 \pm 0.3^{\mathrm{a}}$ & $1.1 \pm 0.4$ & $<0.001$ \\
\hline $\mathrm{E} / \mathrm{E}^{\prime}$ & $22.6 \pm 9.7^{\mathrm{a}, \mathrm{b}}$ & $17.4 \pm 8.5^{\mathrm{a}}$ & $10.0 \pm 2.7$ & $<0.001$ \\
\hline Deceleration time, ms & $169 \pm 56^{\mathrm{a}, \mathrm{b}}$ & $241 \pm 71$ & $226 \pm 50$ & $<0.001$ \\
\hline \multicolumn{5}{|c|}{ Arterial stiffness and wave reflections } \\
\hline cf-PWV, m/s & $12.2 \pm 4.9$ & $12.7 \pm 3.9^{\mathrm{a}}$ & $10.3 \pm 4.0$ & 0.027 \\
\hline cAI, $\%$ & $10.4 \pm 31.9^{a, b}$ & $25.5 \pm 13.9$ & $22.3 \pm 16.2$ & 0.017 \\
\hline \multicolumn{5}{|c|}{ Mechanical properties of CCA } \\
\hline Carotid Einc, $\mathrm{kPa}$ & $1,295 \pm 496^{\mathrm{a}, \mathrm{b}}$ & $1,017 \pm 503^{\mathrm{a}}$ & $719 \pm 322$ & $<0.001$ \\
\hline$\beta$ Stiffness index & $10.7 \pm 4.9^{\mathrm{a}, \mathrm{b}}$ & $7.7 \pm 3.8^{\mathrm{a}}$ & $5.5 \pm 1.9$ & $<0.001$ \\
\hline $\mathrm{CD}, \mathrm{kPa}^{-1} \times 10^{-3}$ & $15.0 \pm 6.9^{a}$ & $19.0 \pm 8.9^{a}$ & $24.4 \pm 9.3$ & $<0.001$ \\
\hline Carotid CS, \% & $1.3 \pm 0.9^{\mathrm{a}, \mathrm{b}}$ & $2.0 \pm 0.8$ & $2.2 \pm 0.9$ & $<0.001$ \\
\hline
\end{tabular}

Figures are means \pm SD unless indicated otherwise. CAD = Coronary artery disease; ACEI/ARB = angiotensin-converting enzyme inhibitor or angiotensin receptor blocker; CCB = calcium channel blocker; eGFR = estimated glomerular filtration rate; RWT $=$ relative wall thickness. ${ }^{\mathrm{a}} \mathrm{p}<0.05$, compared to the normal LV function group. ${ }^{\mathrm{b}} \mathrm{p}<0.05$, compared to the diastolic dysfunction group.

normal LV function were smokers. In addition, patients with LV systolic dysfunction were more likely to take angiotensin-converting enzyme inhibitors or angiotensin receptor blockers, $\beta$-blockers, and diuretics, indicating that these patients had been well treated. Patients with LV systolic dysfunction had significantly lower brachial SBP, DBP and MBP, and carotid SBP than patients with LV diastolic dysfunction. Heart rate was significantly greater 
Table 2. Correlates of arterial stiffness with cardiac structure and function by multiple linear regression analyses

\begin{tabular}{|c|c|c|c|c|c|c|c|c|c|c|}
\hline & \multicolumn{2}{|c|}{ LVM index $\left(\mathrm{g} / \mathrm{m}^{2}\right)$} & \multicolumn{2}{|c|}{ LVEDV index $\left(\mathrm{ml} / \mathrm{m}^{2}\right)$} & \multicolumn{2}{|c|}{ LV EF (\%) } & \multicolumn{2}{|l|}{$\mathrm{E} / \mathrm{A}$} & \multicolumn{2}{|l|}{$\mathrm{E} / \mathrm{E}^{\prime}$} \\
\hline & model 1 & model 2 & model 1 & model 2 & model 1 & model 2 & model 1 & model 2 & model 1 & model 2 \\
\hline cf-PWV (m/s) & 0.092 & - & $0.328^{*}$ & - & $-0.471^{* *}$ & - & 0.124 & - & 0.210 & - \\
\hline Carotid Einc $(\mathrm{kPa})$ & $0.184^{*}$ & 0.179 & $0.426^{* *}$ & $0.398^{* *}$ & $-0.398^{* *}$ & $-0.351^{* *}$ & 0.134 & 0.122 & $0.310^{* *}$ & $0.294^{* *}$ \\
\hline$\beta$ Stiffness index & $0.195^{*}$ & 0.190 & $0.454^{* *}$ & $0.431^{* *}$ & $-0.431^{* *}$ & $-0.394^{* *}$ & 0.086 & 0.076 & $0.285^{* *}$ & $0.271^{* *}$ \\
\hline $\mathrm{CD}\left(\mathrm{kPa}^{-1} \times 10^{-3}\right)$ & $-0.258^{* *}$ & $-0.254^{*}$ & $-0.410^{* *}$ & $-0.381^{* *}$ & $0.384^{* *}$ & $0.336^{* *}$ & $-0.195^{*}$ & $-0.185^{*}$ & $-0.299 * *$ & $-0.282^{* *}$ \\
\hline Carotid CS (\%) & -0.089 & -0.084 & $-0.231^{*}$ & $-0.212^{* *}$ & $0.277^{* *}$ & $0.249^{* *}$ & 0.134 & 0.143 & $-0.223^{*}$ & $-0.211^{*}$ \\
\hline
\end{tabular}

Model 1: accounting for age and brachial MBP. Model 2: accounting for age, brachial MBP, and cf-PWV. ${ }^{*} \mathrm{p}<0.05 ;{ }^{* *} \mathrm{p}<0.01$.

Table 3. Association of arterial stiffness with impaired LV function: logistic regression analysis

\begin{tabular}{|c|c|c|c|c|c|c|}
\hline & \multicolumn{2}{|l|}{ Model 1} & \multicolumn{2}{|l|}{ Model 2} & \multicolumn{2}{|l|}{ Model 3} \\
\hline & OR $(95 \% \mathrm{CI})$ & $\mathrm{p}$ value & OR $(95 \% \mathrm{CI})$ & $\mathrm{p}$ value & OR $(95 \% \mathrm{CI})$ & $\mathrm{p}$ value \\
\hline cf-PWV (1 SD = $4.3 \mathrm{~m} / \mathrm{s}$ ) & $1.70(1.13-2.54)$ & 0.010 & $1.97(1.07-3.65)$ & 0.030 & - & - \\
\hline Carotid Einc $(1 \mathrm{SD}=473 \mathrm{kPa})$ & $3.19(1.89-5.38)$ & $<0.001$ & $3.33(1.92-5.76)$ & $<0.001$ & $3.19(1.84-5.54)$ & $<0.001$ \\
\hline$\beta$ Stiffness index $(1 \mathrm{SD}=3.8)$ & $2.88(1.74-4.79)$ & $<0.001$ & $3.05(1.80-5.18)$ & $<0.001$ & $2.97(1.74-5.05)$ & $<0.001$ \\
\hline $\mathrm{CD}\left(1 \mathrm{SD}=9.5 \mathrm{kPa}^{-1} \times 10^{-3}\right)$ & $0.37(0.22-0.62)$ & $<0.001$ & $0.35(0.20-0.62)$ & $<0.001$ & $0.38(0.21-0.66)$ & 0.001 \\
\hline Carotid CS (1 SD = 0.96\%) & $0.52(0.33-0.80)$ & 0.003 & $0.54(0.35-0.83)$ & 0.006 & $0.55(0.36-0.86)$ & 0.008 \\
\hline
\end{tabular}

Model 1: crude ratio. Model 2: accounting for age, sex, and brachial MBP. Model 3: accounting for age, sex, brachial MBP and cf-PWV.

in patients with LV systolic dysfunction than in other groups. LV EF increased significantly, and the LVEDV index and E/E' decreased significantly, in the order of LV systolic dysfunction, diastolic dysfunction, and normal function. Patients with LV systolic or diastolic dysfunction had a significantly greater LVM index than patients with normal LV function. Patients with LV systolic dysfunction had a significantly greater E/A ratio, a shorter deceleration time, and smaller relative wall thickness than patients with LV diastolic dysfunction or normal LV function.

Patients with LV systolic dysfunction were characterized by a low cAI when compared with the other groups. On the other hand, patients with LV diastolic dysfunction had significantly greater cf-PWV than patients with normal LV function. CCA stiffness tended to increase in the order of normal LV function, LV diastolic dysfunction, and LV systolic dysfunction. All measures of CCA stiffness were significantly greater in patients with LV systolic dysfunction than those in patients with normal LV function.

\section{Coupling of Arterial Stiffness with LV Structure and Function}

In the whole study population, cf-PWV significantly correlated with LVEDV index and LV EF but not LVM index, E/A or E/E', when age and brachial MBP were accounted for (table 2). In contrast, CCA stiffness was apparently coupled with LV structure and systolic and diastolic function. All measures of CCA stiffness correlated significantly with LVEDV index, LV EF, and E/E' with adjustments for age and brachial MBP (table 2, model 1). In addition, CCA Einc, $\beta$ stiffness index, and CD significantly correlated with LVM index, and CCA CD significantly correlated with E/A. With further adjustment for cf-PWV (table 2, model 2), all measures of CCA stiffness remained significantly correlated with LVEF, LVEDV index, and E/E'. In addition, CCA CD remained significantly correlated with LVM index and E/A. 
Sung et al.: Common Carotid Artery Stiffness Is Associated with Left Ventricular Structure and Function and Predicts First Hospitalization for Acute Heart Failure

Table 4. Prediction of first hospitalization for AHF by the highest or lowest quartile of an individual parameter

\begin{tabular}{|c|c|c|c|}
\hline Variable & Quartile cutoff value & Hazard ratio $(95 \% \mathrm{CI})$ & $\mathrm{p}$ value \\
\hline $\mathrm{E} / \mathrm{E}^{\prime}$ & 17.5 & $26.20(3.28-209.56)$ & 0.002 \\
\hline $\mathrm{LV} \mathrm{EF}^{\mathrm{a}}, \%$ & 47 & $11.44(2.37-55.14)$ & 0.002 \\
\hline LVM index, $\mathrm{g} / \mathrm{m}^{2}$ & 138 & $11.06(2.30-53.29)$ & 0.003 \\
\hline Carotid $\mathrm{CS}^{\mathrm{a}}, \%$ & 1.2 & $6.82(1.70-27.35)$ & 0.007 \\
\hline LVEDV index, $\mathrm{ml} / \mathrm{m}^{2}$ & 67 & $6.57(1.64-26.32)$ & 0.008 \\
\hline Carotid Einc, kPa & 1,200 & $6.56(1.64-26.26)$ & 0.008 \\
\hline$\beta$ Stiffness index & 11.1 & $3.91(1.05-14.57)$ & 0.042 \\
\hline $\mathrm{eGFR}^{\mathrm{a}}, \mathrm{ml} / \mathrm{min} / 1.73 \mathrm{~m}^{2}$ & 53.8 & $2.70(0.72-10.08)$ & 0.140 \\
\hline $\mathrm{CD}^{\mathrm{a}}, \mathrm{kPa}^{-1} \times 10^{-3}$ & 14.1 & $2.51(0.67-9.34)$ & 0.171 \\
\hline Age, years & 81 & $1.94(0.48-7.76)$ & 0.351 \\
\hline Brachial PP, mm Hg & 59 & $1.82(0.45-7.33)$ & 0.397 \\
\hline Carotid SBP, mm Hg & 128 & $1.70(0.43-6.82)$ & 0.452 \\
\hline cf-PWV, m/s & 13.9 & $1.62(0.41-6.51)$ & 0.494 \\
\hline Carotid PP, mm Hg & 47 & $1.47(0.37-5.88)$ & 0.586 \\
\hline $\mathrm{E} / \mathrm{A}$ & 1.4 & $1.47(0.37-5.88)$ & 0.586 \\
\hline Brachial SBP, mm Hg & 139 & $0.95(0.29-4.59)$ & 0.952 \\
\hline cAI, \% & 33.2 & $0.89(0.19-4.30)$ & 0.887 \\
\hline
\end{tabular}

eGFR = Estimated glomerular filtration rate. ${ }^{\text {a }}$ Hazard ratio of the lowest quartile.

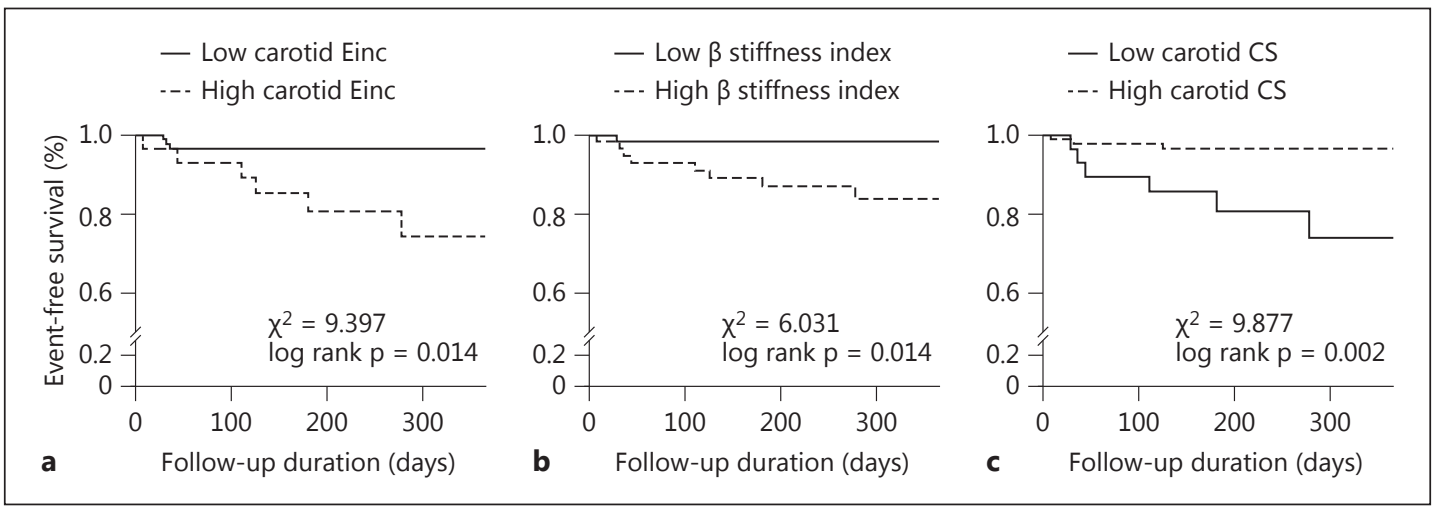

Fig. 2. Kaplan-Meier survival analysis of the development of AHF for subjects with high or low carotid Einc (75-percentile value, 1,200 kPa) (a), carotid $\beta$ stiffness index (median value, 7.7) (b), and carotid CS (25-percentile value, $1.21 \%$ ) (c).

\section{Association of Arterial Stiffness with Impaired LV Function}

All measures of arterial stiffness, including cf-PWV, CCA Einc, $\beta$ stiffness index, CD, and CS, were significantly associated with the presence of either systolic or diastolic LV dysfunction (table 3, model 1). After adjustments for age, sex, and brachial MBP, the associations remained significant (table 3, model 2). With further adjustment for cf-PWV, all measures of CCA stiffness remained significant predictors of impaired LV function (table 3, model 3).

\section{Prediction of the Development of AHF}

During a mean follow-up of $265 \pm 106$ days, 9 patients (6 patients with LV systolic dysfunction and 3 with LV diastolic dysfunction at baseline) had AHF. N-terminal pro-brain natriuretic peptide levels were available in 5 patients (average 4,011 $\pm 2,711 \mathrm{pg} / \mathrm{ml}$ ). Major 
predictors of AHF were measures of cardiac function and structure (table 4). In addition, the simple Cox proportional regression analyses also identified the highest quartiles of CCA Einc (75-percentile value, $1,200 \mathrm{kPa}$ ) and $\beta$ stiffness index (75-percentile value, 11.1), and the lowest quartile of CCA CS (25-percentile value, 1.2\%) as significant predictors of AHF (table 4). In contrast, neither cf-PWV nor cAI was associated with the incidence of AHF. The KaplanMeier survival curve analysis also showed that high CCA Einc, high $\beta$ stiffness index, and low CCA CS were significantly associated with a higher event rate of AHF (fig. 2).

\section{Discussions}

Pulsatile hemodynamics may play an important role in the pathogenesis of heart failure with reduced [3] and preserved EF [29], and cf-PWV in particular may complement the diagnosis of heart failure with preserved EF [30]. cf-PWV is the most widely accepted indicator of arterial stiffness, covering the territory of CCA but excluding the ascending aorta. However, the present study found that measures of CCA stiffness consistently increased in patients with LV systolic and diastolic dysfunction and were significantly coupled with measures of LV structure and systolic and diastolic function, over and above cf-PWV. Moreover, measures of CCA stiffness but not cf-PWV predicted the development of first hospitalization due to AHF. Given that the CCA stiffness is not the major afterload of the left ventricle, it may be considered as a surrogate for proximal aortic stiffness, which may be more important than cf-PWV in the pathogenesis of heart failure. The results complement the recent findings that carotid artery stiffness is associated with exercise intolerance in patients with preserved EF heart failure [9, 20], and may suggest that an increase in CCA stiffness beyond the changes attributed to normal aging is involved in the pathogenesis of heart failure [20].

The proximal aortic root may be crucial to the development of heart failure $[3,5,6]$. It has been shown that elderly patients with preserved or reduced EF heart failure have reduced proximal thoracic aortic distensibility that may contribute to their severe exercise intolerance [5, 31]. In patients with heart failure with reduced EF, the central pulsatile load (characteristic impedance) but not cf-PWV was elevated in comparison to the subjects without heart failure [3]. This may imply that normal vascular aging may not be sufficient to cause heart failure and cf-PWV may underestimate, and thus is inappropriate in the assessment of the proximal aortic stiffness.

The impedance mismatch between the proximal aorta and CCA may disappear with a disproportionate increase in aortic impedance [14], so the proximal aorta and CCA may become a common conduit with remarkably reduced wave reflection at the interface [14]. On the one hand, the impedance matching may facilitate the transmission of the excessive pulsatile energy and damage the cerebral microcirculation [14]. On the other hand, the CCA may become a 'window' to access the mechanical properties of the proximal aorta. In patients with heart failure and preserved EF, the carotid SBP, PP, PP amplification, and CCA Peterson's modulus but not brachial blood pressures, total peripheral resistance or cf-PWV were substantially elevated at rest and dramatically increased when compared with controls [9]. The study further demonstrated that CCA stiffness rather than cf-PWV was the determinant of exercise intolerance, further emphasizing the importance of proximal aortic stiffness in patients with heart failure and preserved $\mathrm{EF}$ [9].

Previous studies have demonstrated the usefulness of CCA stiffness as a risk factor for cardiovascular disease [32-35]. The present study expanded the usefulness of CCA stiffness in the risk stratification of patients at risk of developing heart failure. Moreover, the present study also showed that CCA stiffness can be easily and effectively assessed using the speckletracking semi-automatically derived CCA CS, which may be superior to Einc or $\beta$ stiffness 
index in the assessment of vascular aging [36]. However, the results of the present study do not suggest that CCA stiffness may effectively replace cf-PWV as the gold standard for the assessment of arterial stiffness in the general population [37].

\section{Study Limitations}

Firstly, cf-PWV and CD were significantly related to cardiac structure and functions but could not predict the development of AHF, which might also be the result of insufficient power to detect significance due to the limited sample size and number of events in the present study. For the same reason, we did not compare the LV systolic versus diastolic dysfunction subgroups concerning the risk of development of AHF. While the CCA stiffness parameters demonstrated identical and constant associations with LV functions, the independency of their prognostic value should be tested in future studies with larger populations. Secondly, the study was a secondary analysis for subjects participating in another hemodynamic study. Therefore, the study may be subject to selection bias, despite its prospective nature. Thirdly, we did not measure the pulsatile hemodynamics during exercise. Because arterial stiffness may be underestimated at rest in patients with preserved EF heart failure [9], the true impact of CCA stiffness on LV structure and function and the development of AHF may have been underestimated in the present study.

\section{Conclusions}

In patients at risk of developing heart failure, mechanical properties of CCA may be associated with LV structure and function and predict the first AHF independently of arterial stiffness indexed by cf-PWV. The usefulness of CCA stiffness in the risk stratification of patients at risk of developing heart failure needs to be confirmed in future studies with larger study populations.

\section{Disclosure Statement}

The authors have no conflicts of interest to declare.

\section{References}

1 Chae CU, Pfeffer MA, Glynn RJ, Mitchell GF, Taylor JO, Hennekens CH: Increased pulse pressure and risk of heart failure in the elderly. JAMA 1999;281:634-639.

-2 Vaccarino V, Holford TR, Krumholz HM: Pulse pressure and risk for myocardial infarction and heart failure in the elderly. J Am Coll Cardiol 2000;36:130-138.

-3 Mitchell GF, Tardif JC, Arnold JM, Marchiori G, O’Brien TX, Dunlap ME, Pfeffer MA: Pulsatile hemodynamics in congestive heart failure. Hypertension 2001;38:1433-1439.

4 Mitchell GF: Effects of central arterial aging on the structure and function of the peripheral vasculature: implications for end-organ damage. J Appl Physiol 2008;105:1652-1660.

-5 Hundley WG, Kitzman DW, Morgan TM, Hamilton CA, Darty SN, Stewart KP, Herrington DM, Link KM, Little WC: Cardiac cycle-dependent changes in aortic area and distensibility are reduced in older patients with isolated diastolic heart failure and correlate with exercise intolerance. J Am Coll Cardiol 2001;38:796-802.

6 Pepine CJ, Nichols WW, Conti CR: Aortic input impedance in heart failure. Circulation 1978;58:460-465.

7 Yu WC, Chuang SY, Lin YP, Chen CH: Brachial-ankle vs carotid-femoral pulse wave velocity as a determinant of cardiovascular structure and function. J Hum Hypertens 2008;22:24-31.

-8 Desai AS, Mitchell GF, Fang JC, Creager MA: Central aortic stiffness is increased in patients with heart failure and preserved ejection fraction. J Card Fail 2009;15:658-664.

$\rightarrow 9$ Tartiere-Kesri L, Tartiere JM, Logeart D, Beauvais F, Cohen Solal A: Increased proximal arterial stiffness and cardiac response with moderate exercise in patients with heart failure and preserved ejection fraction. J Am Coll Cardiol 2012;59:455-461. 
10 Mitchell GF, Hwang SJ, Vasan RS, Larson MG, Pencina MJ, Hamburg NM, Vita JA, Levy D, Benjamin EJ: Arterial stiffness and cardiovascular events: the Framingham Heart Study. Circulation 2010;121:505-511.

-11 Sutton-Tyrrell K, Najjar SS, Boudreau RM, Venkitachalam L, Kupelian V, Simonsick EM, Havlik R, Lakatta EG, Spurgeon H, Kritchevsky S, Pahor M, Bauer D, Newman A: Elevated aortic pulse wave velocity, a marker of arterial stiffness, predicts cardiovascular events in well-functioning older adults. Circulation 2005;111:33843390.

12 Chen CH, Ting CT, Nussbacher A, Nevo E, Kass DA, Pak P, Wang SP, Chang MS, Yin FCP: Validation of carotid artery tonometry as a means of estimating augmentation index of ascending aortic pressure. Hypertension 1996;27:168-175.

13 Wang KL, Cheng HM, Chuang SY, Spurgeon HA, Ting CT, Lakatta EG, Yin FCP, Chou P, Chen CH: Central or peripheral systolic or pulse pressure: which best relates to target organs and future mortality? J Hypertens 2009;27:461-467.

14 Mitchell GF, van Buchem MA, Sigurdsson S, Gotal JD, Jonsdottir MK, Kjartansson O, Garcia M, Aspelund T, Harris TB, Gudnason V, Launer LJ: Arterial stiffness, pressure and flow pulsatility and brain structure and function: the Age, Gene/Environment Susceptibility-Reykjavik study. Brain 2011;134:3398-3407.

15 Yang EY, Chambless L, Sharrett AR, Virani SS, Liu X, Tang Z, Boerwinkle E, Ballantyne CM, Nambi V: Carotid arterial wall characteristics are associated with incident ischemic stroke but not coronary heart disease in the Atherosclerosis Risk in Communities (ARIC) study. Stroke 2012;43:103-108.

-16 Tsivgoulis G, Vemmos K, Papamichael C, Spengos K, Daffertshofer M, Cimboneriu A, Zis V, Lekakis J, Zakopoulos N, Mavrikakis M: Common carotid arterial stiffness and the risk of ischaemic stroke. Eur J Neurol 2006; 13:475-481.

17 Morovic S, Jurasic MJ, Martinic Popovic I, Seric V, Lisak M, Demarin V: Vascular characteristics of patients with dementia. J Neurol Sci 2009;283:41-43.

18 Jurasic MJ, Popovic IM, Morovic S, Trkanjec Z, Seric V, Demarin V: Can beta stiffness index be proposed as risk factor for dementia. J Neurol Sci 2009;283:13-16.

19 Myung Y, Seo HS, Jung IH, Lee NH, Suh J, Choi JH, Cho YH: The correlation of carotid artery stiffness with heart function in hypertensive patients. J Cardiovasc Ultrasound 2012;20:134-139.

20 Kitzman DW, Herrington DM, Brubaker PH, Moore JB, Eggebeen J, Haykowsky MJ: Carotid arterial stiffness and its relationship to exercise intolerance in older patients with heart failure and preserved ejection fraction. Hypertension 2013;61:112-119.

-21 McMurray JJ, Adamopoulos S, Anker SD, Auricchio A, Bohm M, Dickstein K, Falk V, Filippatos G, Fonseca C, Gomez-Sanchez MA, Jaarsma T, Kober L, Lip GY, Maggioni AP, Parkhomenko A, Pieske BM, Popescu BA, Ronnevik PK, Rutten FH, Schwitter J, Seferovic P, Stepinska J, Trindade PT, Voors AA, Zannad F, Zeiher A; ESC Committee for Practice Guidelines: ESC guidelines for the diagnosis and treatment of acute and chronic heart failure 2012: the Task Force for the Diagnosis and Treatment of Acute and Chronic Heart Failure 2012 of the European Society of Cardiology. Developed in collaboration with the Heart Failure Association (HFA) of the ESC. Eur Heart J 2012;33:1787-1847.

-22 Yancy CW, Jessup M, Bozkurt B, Masoudi FA, Butler J, McBride PE, Casey DE Jr, McMurray JJ, Drazner MH, Mitchell JE, Fonarow GC, Peterson PN, Geraci SA, Horwich T, Januzzi JL, Johnson MR, Kasper EK, Levy WC, Riegel B, Sam F, Stevenson LW, Tang WH, Tsai EJ, Wilkoff BL: 2013 ACCF/AHA guideline for the management of heart failure: a report of the American College of Cardiology Foundation/American Heart Association Task Force on Practice Guidelines. J Am Coll Cardiol 2013;62:e147-e239.

-23 Ma YC, Zuo L, Chen JH, Luo Q, Yu XQ, Li Y, Xu JS, Huang SM, Wang LN, Huang W, Wang M, Xu GB, Wang HY: Modified glomerular filtration rate estimating equation for Chinese patients with chronic kidney disease. J Am Soc Nephrol 2006;17:2937-2944.

-24 Paulus WJ, Tschope C, Sanderson JE, Rusconi C, Flachskampf FA, Rademakers FE, Marino P, Smiseth OA, De Keulenaer G, Leite-Moreira AF, Borbely A, Edes I, Handoko ML, Heymans S, Pezzali N, Pieske B, Dickstein K, Fraser AG, Brutsaert DL: How to diagnose diastolic heart failure: a consensus statement on the diagnosis of heart failure with normal left ventricular ejection fraction by the Heart Failure and Echocardiography Associations of the European Society of Cardiology. Eur Heart J 2007;28:2539-2550.

-25 Sung SH, Yu WC, Cheng HM, Lee CW, Lin MM, Chuang SY, Chen CH: Excessive wave reflections on admission predict post-discharge events in patients hospitalized due to acute heart failure. Eur J Heart Fail 2012;14: 1348-1355.

-26 London GM, Guerin AP, Marchais SJ, Pannier B, Safar ME, Day M, Metivier F: Cardiac and arterial interactions in end-stage renal disease. Kidney Int 1996;50:600-608.

27 Kawasaki T, Sasayama S, Yagi S, Asakawa T, Hirai T: Non-invasive assessment of the age related changes in stiffness of major branches of the human arteries. Cardiovasc Res 1987;21:678-687.

-28 McKee PA, Castelli WP, McNamara PM, Kannel WB: The natural history of congestive heart failure: the Framingham study. N Engl J Med 1971;285:1441-1446.

-29 Weber T, O’Rourke MF, Ammer M, Kvas E, Punzengruber C, Eber B: Arterial stiffness and arterial wave reflections are associated with systolic and diastolic function in patients with normal ejection fraction. Am J Hypertens 2008;21:1194-1202.

-30 Weber T, Wassertheurer S, O’Rourke MF, Haiden A, Zweiker R, Rammer M, Hametner B, Eber B: Pulsatile hemodynamics in patients with exertional dyspnea: potentially of value in the diagnostic evaluation of suspected heart failure with preserved ejection fraction. J Am Coll Cardiol 2013;61:1874-1883. 
-31 Rerkpattanapipat P, Hundley WG, Link KM, Brubaker PH, Hamilton CA, Darty SN, Morgan TM, Kitzman DW: Relation of aortic distensibility determined by magnetic resonance imaging in patients $>$ or $=60$ years of age to systolic heart failure and exercise capacity. Am J Cardiol 2002;90:1221-1225.

-32 Tomiyama H, Yamashina A: Non-invasive vascular function tests: their pathophysiological background and clinical application. Circ J 2010;74:24-33.

-33 Zoungas S, Cameron JD, Kerr PG, Wolfe R, Muske C, McNeil JJ, McGrath BP: Association of carotid intima-medial thickness and indices of arterial stiffness with cardiovascular disease outcomes in CKD. Am J Kidney Dis 2007; 50:622-630.

-34 Nunez F, Martinez-Costa C, Sanchez-Zahonero J, Morata J, Chorro FJ, Brines J: Carotid artery stiffness as an early marker of vascular lesions in children and adolescents with cardiovascular risk factors. Rev Esp Cardiol 2010;63:1253-1260.

35 Stein JH, Korcarz CE, Hurst RT, Lonn E, Kendall CB, Mohler ER, Najjar SS, Rembold CM, Post WS; American Society of Echocardiography Carotid Intima-Media Thickness Task Force: Use of carotid ultrasound to identify subclinical vascular disease and evaluate cardiovascular disease risk: a consensus statement from the American Society of Echocardiography Carotid Intima-Media Thickness Task Force. Endorsed by the Society for Vascular Medicine. J Am Soc Echocardiogr 2008;21:93-111, quiz 189-190.

-36 Bjallmark A, Lind B, Peolsson M, Shahgaldi K, Brodin LA, Nowak J: Ultrasonographic strain imaging is superior to conventional non-invasive measures of vascular stiffness in the detection of age-dependent differences in the mechanical properties of the common carotid artery. Eur J Echocardiogr 2010;11:630-636.

37 Mancia G, Fagard R, Narkiewicz K, Redon J, Zanchetti A, et al: 2013 ESH/ESC guidelines for the management of arterial hypertension: the Task Force for the Management of Arterial Hypertension of the European Society of Hypertension (ESH) and of the European Society of Cardiology (ESC). Eur Heart J 2013;34:2159-2219. 